\title{
Os sistemas de organização do conhecimento nas perspectivas atuais das normas internacionais de construção
}

\author{
The knowledge organization systems in the current perspectives of the international guides \\ for the construction
}

\begin{abstract}
Vera Regina Casari Boccato
Doutora em Ciência da Informação pela Faculdade de Filosofia e Ciências da UNESP. Professora adjunta do Departamento de Ciência da Informação da Universidade Federal de São Carlos, UFSCar.

E-mail: vboccato@ufscar.br
\end{abstract}

\section{Resumo}

Realizou-se um estudo dos sistemas de organização do conhecimento pelas perspectivas das normas internacionais de construção, verificando-se as ampliações e as modificações mais significativas ocorridas entre elas, a partir dos vocabulários controlados abordados. O objetivo é apresentar as concepções, as funções e características de cada um deles, delimitando e, ao mesmo tempo, generalizando suas aplicações nos mais diversos contextos de uso, pelas perspectivas evolutivas das normas internacionais para a Organização e Recuperação da Informação em Ciência da Informação. O universo de pesquisa foram as normas internacionais ANSI/NISO Z39.19-2005, BS 8723 e ISO 25964, com destaque para as os sistemas de classificação, listas de cabeçalhos de assunto, taxonomias, tesauros e ontologias, além dos anéis de sinônimos, sistemas de classificação de negócios para gerenciamento de registros e redes semânticas como vocabulários controlados analisados. Os resultados deste estudo apontaram, principalmente, a necessidade contínua de atualização das normas internacionais, frente às inovações tecnológicas e informacionais ocorridas na Organização e Recuperação do Conhecimento em Ciência da Informação e no contexto do usuário especializado ou não.

Palavras-chave: Normas internacionais. Construção. Sistemas de organização do conhecimento. Sistema de recuperação da informação. Ambiente web.

\begin{abstract}
We conducted a study of the knowledge organization systems for the perspectives of international standards for the construction, verifying the extensions and the most significant changes occurred between them from the controlled vocabulary addressed. The aim is to present the concepts, functions and characteristics of each, and delimiting, at the same time, generalizing their applications in various contexts of use, for the perspectives of international standards for the Information Organization and Retrieval in Information Science. The research base was the international standards ANSI/NISO Z39.19-2005, BS 8723 and ISO 25964, especially the classification schemes, subject headings schemes, taxonomies, thesauri and ontologies, as well as synonyn rings, business classification schemes for records management and semantic networks as controlled vocabularies analyzed. The results of this study showed, mainly, on the continuing need to update international standards, for the technological innovations and informational occurred in Knowledge Organization and Retrieval in Information Science and in the specialized or not users' context.
\end{abstract}

Keywords: International Standards. Construction. Knowledge organization systems. Information Retrieval System. Web environment. 


\section{Introdução}

O mundo contemporâneo norteado pelo desenvolvimento tecnológico nos conduz a mudanças e reflexões sobre instrumentos e tratamento, acesso e busca da informação para diferentes usuários de unidades e ambientes de informação diversos.

As unidades de informação são, “[...] organizações sociais sem fins lucrativos”, “[...] voltadas para a aquisição, processamento, armazenamento e disseminação de informações" [...] para os indivíduos e a sociedade, de forma tangível (produtos impressos), ou intangível (prestação de serviços personalizados, pessoais, e hoje, cada vez mais, de forma virtual - em linha, pela Internet)". (TAPARANOFF; ARAÚJO JÚNIOR; CORMIER, 2000, p. 92).

Os ambientes informacionais estão relacionados com os ambientes organizacionais e externos dessas organizações. São formados a partir de seis dimensões que envolvem: 1) a informação como uso estratégico; 2) políticas de informação; 3) cultura e comportamento informacional; 4) equipe da informação; 5) Processo da informação; 6) arquitetura da informação. (DAVENPORT, 2001).

Para Cassar (2003, p. 15), uma organização é a “[...] união de diversas pessoas, que se reúnem na busca de objetivos comuns claramente definidos, por um prazo determinado ou não [...]".

Tanto quanto os ambientes informacionais, vê-se as unidades de informação constituídas, também, de tal preceito e das seis dimensões apresentados, em que ambos "espaços" devem considerar os valores, as crenças de como os usuários fazem uso da informação a partir de suas cognições e conexões sociais, numa perspectiva sociocognitiva de tratamento, disseminação e uso da informação.

Diante do exposto, as bibliotecas, os centros de documentação, museus, meios de comunicação, entre outros são considerados unidades e ambientes informacionais numa relação de equivalência de significado e de propósito de atuação. Uma vez que este estudo reporta-se a sistemas de organização do conhecimento aplicáveis ao tratamento temático da informação de recursos informacionais (texto, imagem, som) far-se-á o uso do termo "unidades de informação" para caracterizar as bibliotecas tradicionais (constituídas fisicamente) e ambientes informacionais para designar as bibliotecas digitais, virtuais, bem

\footnotetext{
${ }^{1}$ IBICT (1989, p. i) citado por TAPARANOFF; ARAÚJO JÚNIOR; CORMIER (2000, p. 92).

InCID: R. Ci. Inf. e Doc., Ribeirão Preto, v. 2, n. 1, p. 165-192, jan./jun. 2011.
} 
como outros "espaços" de informação disponível na Rede Mundial de Dados - Internet (redes sociais, etc.).

Os sistemas de recuperação da informação de bases de dados eletrônicas, catálogos coletivos informatizados, bancos de dados, repositórios, portais, gerenciadores de publicações eletrônicas, bem como as páginas na web requerem sistemas de organização do conhecimento que permitem a representação temática de recursos informacionais nos meios impresso e eletrônico, armazenados em acervos locais de bibliotecas tradicionais ou em bibliotecas digitais ou virtuais disponíveis na internet.

Tais sistemas de organização do conhecimento, que se referem a instrumentos que possibilitam a organização de estruturas semânticas de conhecimento e caracterizados pelos sistemas de classificação, listas de cabeçalhos de assunto, taxonomias, tesauros, ontologias, entre outros, exigem normas e metodologias adequadas de construção e atualização para finalidades e aplicações específicas.

Para Zeng (2008) os sistemas de organização do conhecimento devem ser delineados a partir de um plano multidimensional, transpondo fronteiras culturais e geográficas de acesso e representação, sem desconsiderar suas funções principais que incluem a eliminação da ambiguidade, o controle de sinônimos e o estabelecimento de relacionamentos semânticos.

Os estudos de Hodge (2000) e do Networked Knowledge Organization Systems/Services (2010) apontam que os sistemas de organização do conhecimento possuem características distintas para determinados contextos de aplicação, em que se destacam duas categorias classificatórias:

1. Classificação e Categorização:

- Sistemas de categorização: genericamente, qualquer sistema organizado;

- Sistemas de classificação bibliográficos: relações hierárquicas e facetadas de notações numéricas ou alfabéticas para representar temas gerais;

- Listas de cabeçalhos de assunto: sistemas basicamente classificatórios, formados por um conjunto de termos para representar os assuntos dos itens de uma coleção de acordo com regras estabelecidas de combinação de termos na constituição de cabeçalhos compostos;

InCID: R. Ci. Inf. e Doc., Ribeirão Preto, v. 2, n. 1, p. 165-192, jan./jun. 2011. 
- taxonomias: divisões de itens ordenados em grupos ou categorias com base em características específicas;

2. Modelos de Relacionamento

- ontologias: modelos conceituais específicos, para representar as relações complexas entre objetos, incluindo as regras e axiomas não presentes nas redes semânticas;

- redes semânticas: conjuntos de termos que representam conceitos, modelados como os nós de uma rede de tipos de relação variável;

- tesauro: conjuntos de termos que representam conceitos e as relações hierárquicas, de equivalência e de associação entre eles.

Vê-se, portanto, um amplo e diversificado cenário e, porque não dizer, complexo, composto por sistemas de organização do conhecimento para a indexação manual, semiautomática, automática e social ${ }^{2}$ de recursos informacionais, visando à localização, a busca e a recuperação para uso em unidades e ambientes de informação.

A partir da classificação realizada por Hodge (2000) e pelo Networked Knowledge Organization Systems/Services (2010) o foco deste estudo recai para os sistemas de organização do conhecimento que promovem a recuperação por assunto dos conteúdos de informação, apresentados, também pelas normas internacionais de construção , com destaque, para os sistemas de classificação, listas de cabeçalhos de assunto, taxonomias, tesauros e ontologias. Também focalizar-se-á os demais sistemas abordados pelas normas internacionais de construção, particularmente os anéis de sinônimos, os sistermas de classificação de negócios para gerenciamento de registros e as redes semânticas. Além disso, faz-se referência às folksonomias, tendo em vista a sua importância como um sistema social de construção do conhecimento.

Para tanto, propõe-se realizar um estudo dos sistemas de organização do conhecimento pelas perspectivas das normas internacionais de construção ANSI/NISO Z39:19-2005, BS 8723 e ISO 25964 (em desenvolvimento), verificando-se as ampliações e as modificações mais significativas ocorridas entre elas a partir dos vocabulários controlados

\footnotetext{
${ }^{2}$ Indexação social refere-se "[...] a ação de etiquetagem [tagging] desempenhada por usuários de ferramentas sociais em ambientes Web. (GUEDES, R. de M.; DIAS, E. J. W. Indexação social: abordagem conceitual. Revista ACB: Biblioteconomia em Santa Catarina, Florianópolis, v.15, n.1, p. 41, jan./jun., 2010.
} 
abordados. O objetivo é apresentar as concepções, as funções e características de cada um deles, delimitando e, ao mesmo tempo, generalizando suas aplicações nos mais diversos contextos de uso, pelas perspectivas atuais das normas internacionais (standards) para a Organização e Recuperação da Informação em Ciência da Informação.

\section{As normas internacionais de construção de sistemas de organização do conhecimento: histórico e apresentação}

Muitas vezes a alta revocação torna-se uma realidade quando se depara com um universo documental de informações acerca dos sistemas de organização do conhecimento, exemplificados pelos artigos científicos, livros, sites (CURRÁS, 2005, ZENG, 2008, BOCCATO, RAMALHO, FUJITA, 2008, GUARIDO, 2008), entre outras fontes que tratam sobre conceitos, estruturas, formatos e a contribuição que cada um deles traz na construção de outros sistemas para a recuperação em ambientes tradicionais e digitais.

Nesse cenário informacional destacam-se, também, as normas internacionais, exemplificadas pela ANSI-NISO Z39:10-2005, BS 8723 e ISO 24965, com suas diretrizes sobre a construção, formato, gestão e uso de sistemas de organização do conhecimento para a representação e recuperação da informação de suportes impressos e eletrônicos em sistemas de informação automatizados ou em outros espaços de informação na web.

A norma ANSI/NISO Z39.19 foi elaborada pela National Information Standards Organization (NISO), pertencente ao American National Standards Institute (ANSI), e teve sua primeira edição publicada em 1974, revisada no ano de 1980, sob o título Thesaurus Structure, Construction and Use. A segunda edição foi disponibilizada em 1993 ANSI/NISO Z39.19-1993: Guidelines for the Construction, Format, and Management of Monolingual Thesauri, tendo sido baseada nas concepções da norma americana ISO 27881986.

Com o crescimento da indústria da informação e, consequentemente, com o advento das bases de dados bibliográficas, houve a necessidade de diretrizes normativas na construção de tesauros disponíveis não só no formato impresso, como também no formato eletrônico, via web

InCID: R. Ci. Inf. e Doc., Ribeirão Preto, v. 2, n. 1, p. 165-192, jan./jun. 2011. 
Assim, a terceira edição foi divulgada em 2003, constituindo a norma ANSI/NISO Z39.19-2003 - Guidelines for the Construction, Format, and Managment of Monolingual Thesauri, com o objetivo de apresentar as regras de construção de tesauros monolíngues impressos e eletrônicos, incluindo a relação entre os termos, com exemplos, sugestões de escolha e redação de descritores, entre outros aspectos.

A expansão da tecnologia e sua aplicabilidade no acesso e na recuperação da informação viabilizou rapidamente a necessidade da revisão da terceira edição da norma ANSI/NISO Z39.19-2003. A quarta edição, publicada em 2005, nomeada por ANSI/NISO Z39:10-2005 - Guidelines for the Construction, Format, and Managment of Monolingual Controlled Vocabularies tem como proposta o estabelecimento de diretrizes e convenções quanto à construção, o formato de apresentação e o gerenciamento de vocabulários controlados, impressos e eletrônicos, focalizando, principalmente, outros tipos de sistemas de organização do conhecimento, além dos tesauros, tais como as listas, os anéis de sinônimos, as taxonomias e as redes semânticas. Ela é composta por onze seções e seis apêndices, assim distribuída:

\section{Introduction}

2. Scope

3. Referenced Standards

4. Definitions, Abbreviations, and Acronyms

5. Controlled Vocabularies - Purpose, Concepts, Principles, and Structure

6. Term Choice, Scope, and Form

7. Compound Terms

8. Relationships

9. Displaying Controlled Vocabularies

10. Interoperability

11. Construction, Testing, Maintenance, and Management Systems Appendixes A-F

InCID: R. Ci. Inf. e Doc., Ribeirão Preto, v. 2, n. 1, p. 165-192, jan./jun. 2011. 
Sobre as atualizações significativas ocorridas na Z39.19-2005, destacam-se, inicialmente, a incorporação de uma outra finalidade às quatro definidas pela norma Z39.192003 para o controle de vocabulários, correspondente ao item "Etiqueta e Navegação", enfatizando ainda mais a construção de vocabulários disponíveis eletronicamente:

1) Tradução: prover um modo para traduzir a linguagem natural dos autores, indexadores e usuários para um vocabulário controlado usado para indexação e recuperação;

2) Consistência: promover consistência na designação de termos de indexação;

3) Indicação de relacionamentos: indicar relacionamentos semânticos entre termos;

4) Etiqueta e navegação: provê hierarquias claras e consistentes em um sistema de navegação para auxiliar usuários na localização de documentos desejados;

5) Recuperação: servir como uma ajuda na busca e recuperação de documentos.

A etiqueta refere-se ao "assunto" do recurso de informação que será rotulado para a "navegação" pelo usuário no ambiente informacional. No contexto da indexação, a etapa da "tradução" será realizada pelo indexador, a partir da escolha do termo mais adequado no vocabulário controlado adotado pelo sistema de informação, previamente identificado e selecionado na etapa da análise de assunto. Na busca por assunto, o usuário fará uso do vocabulário controlado para selecionar os termos que melhor representam as suas necessidades informacionais na elaboração das estratégias de busca para a recuperação precisa da informação.

O estabelecimento de quatro princípios importantes para a construção de vocabulários também foi evidenciado, visando à garantia da consistência de uma rede terminológica quanto:

1) A eliminação de ambiguidades : causadas por homógrafos e polissemias;

2) O controle de sinônimos: sinônimos, quase-sinônimos e variantes lexicais;

3) O estabelecimento das relações lógico-semânticas entre os termos;

4) A aplicação de testes para a validação dos termos. 
A interoperabilidade (mapeamento/mapping) entre vocabulários controlados ${ }^{3}$ ), focalizada pela norma ANSI/NISO Z39:19-2005 na seção 10 - Interoperability, é um ponto de destaque vista como um recurso de construção de sistemas de organização do conhecimento. Aspectos sobre necessidade e os fatores que afetam a interoperabilidade, a construção de vocabulários controlados multilíngues, a fusão de vocabulários controlados, o armazenamento e manutenção das relações entre os termos em vários vocabulários controlados, os métodos de realização da interoperabilidade entre vocabulários controlados, entre outros, são tratados em profundidade, com exemplos e ilustrações que facilitam a compreensão da temática.

Em complementação, o “Appendix D - Methods for Achieving Interoperability" traz o estudo realizado por Marcia Lei Zeng and Lois Cha, publicado em 2004" ${ }^{4}$ arrolando nove possibilidades de realização de interoperabiliadde entre vocabulários controlados: 1) Derivação/Modelização ～(Derivation/Modeling); 2) Tradução/Adaptação (Translation/Adaptation); 3) Vocabulários Controlados Satélite (Satellite Controlled Vocabularies; 4) Nodos ou Nós de Ligação (Node or Leaf Linking); 5) Mapeamento Direto (Direct Mapping); 6) Mapeamento por Co-ocorrência (Co-occurrence Mapping); 6) Comutação ou Linguagem de Intercâmbio (Switching); 8) União Através de uma Lista Temporária (Linking Through a Temporary Union List); 9) União Através de Servidores de Vocabulário Controlado (Linking Through Controlled Vocabulary Servers). (Tradução nossa).

Uma outra proposta realizada pelo padrão ANSI/NISO Z39.19-2005 foi a inclusão da análise facetada para a elaboração de vocabulários controlados, seguindo os princípios de Ranganathan $^{5}$ que incluem cinco categorias fundamentais para a organização e representação dos assuntos: Personalidade (Personality), Material (Material), Energia (Energy), Espaço (Space) e Tempo ( Time), mnemonicamente conhecido como PMEST.

Sobre a norma britânica BS 8723 (British Standard 8723), esta teve sua trajetória marcada pelo desenvolvimento, inicialmente de duas edições que se configuraram, respectivamente, nas normas BS 5723, publicadas em abril de 1979 e posteriormente em setembro de 1987, ambas as edições denominadas por Guidelines for the establishment and

\footnotetext{
${ }^{3}$ No contexto das normas internacionais de construção, formato e gerenciamento utiliza-se a denominação "vocabulários controlados" em substituição ao termo "sistemas de organização do conhecimento".

${ }^{4}$ ZENG, M. L.; CHAN, L. M. Trends and issues in establishing interoperability among knowledge organization systems. journal of the american society for information science and technology, New York, v. 55, n. 5., p. :377395, 2004.

${ }^{5}$ RANGANATHAN, S. R. Prolegomena to library classification. 3rd ed. Bombay, Asia Publ. House, 1967.
}

InCID: R. Ci. Inf. e Doc., Ribeirão Preto, v. 2, n. 1, p. 165-192, jan./jun. 2011. 
development of monolingual thesauri. Essas normas (BS 5723-1979, BS 5723-1987) tiveram como correspondentes a norma ISO 2788-1986.

A BS 5723 traz como ponto focal a construção de tesauros monolingues, com destaque para os relacionamentos conceituais, simbologias e abreviaturas empregadas, formas de apresentação e gestão. No contexto de construção dos tesauros multilíngues, encontra-se a BS 6723, equivalendo-se a norma a ISO 5964, ambas publicadas no mesmo ano de 1985.

Por sua vez e tendo em vista os diversos sistemas de organização do conhecimento disponíveis na atualidade, as normas BS 5723-1987 e 6723-1985 foram unificadas e ampliadas as suas atuações para outras formas e estruturas de organização do conhecimento e de intercâmbio de dados padronizados. Nesse sentido, destaca-se a norma BS8723 Structured vocabularies for information retrieval - guide, publicada entre 2005 e 2008, composta por cinco partes:

1. Definitions, symbols and abbreviations.

2. Thesauri.

3. Part 2: Thesauri 3. Vocabularies other than thesauri: contempla outros tipos de sistemas de organização do conhecimento, tais como os sistemas de classificação, sistemas de classificação de negócios para gerenciamento de registros, listas de cabeçalhos de assunto, taxonomias, redes semânticas e ontologias.

4. Part 3: Vocabularies other than thesauri 4. Interoperability between vocabularies: arrola diretrizes sobre os tesauros multilíngues e apresenta situações em que mais de um idioma ou vocabulário está em uso, mas o acesso a todos os recursos informacionais torna-se necessário ser realizado por meio do vocabulário escolhido pelo usuário. Também focaliza situações em que um tesauro interage com um ou mais tipos diferentes de vocabulário controlado, exemplificadas pelos casos de vocabulários que não possuem sistemas de coordenação de termos idênticos para a prática da interoperabilização.

5. Interoperation between vocabularies and other components of information storage and retrieval systems: focaliza a necessidade dos vocabulários trabalharem com os motores de busca; trata sobre os sistemas de gestão de conteúdos e os softwares de publicação na web, etc. Além disso, define os protocolos e formatos necessários para o intercâmbio de dados dos vocabulários.

InCID: R. Ci. Inf. e Doc., Ribeirão Preto, v. 2, n. 1, p. 165-192, jan./jun. 2011. 
No que diz respeito a norma ISO 25964 (International Organization for Standardization 25964), ela encontra-se em desenvolvimento e tem como base a norma BS 8723 - Structured vocabularies for Information retrieval - guide. Ela foi estruturada em duas partes, tendo sido publicadas as edições preliminares (draft) para uso e posteriores ajustes que se fizerem necessários. São elas:

1. ISO/FDS 25964-1: Information and documentation -- Thesauri and interoperability with other vocabularies -- Part 1: Thesauri for information retrieval $l^{6}$ : abrange todos os aspectos lexicais, monolíngues e multilíngues, incluindo um modelo de dados, formatos e protocolos para intercâmbio de dados. Amplia as orientações sobre a construção e gestão de tesauros; traz diretrizes sobre a aplicação da análise facetada na construção de tesauros e especificações sobre a funcionalidade de softwares para a gestão.

2. ISO/CD 25964-2: Information and documentation -- Thesauri and interoperability with other vocabularies -- Part 2: Interoperability with other vocabularies ${ }^{7}$ : arrola a interoperabilidade entre tesauros e outros vocabulários controlados, com destaque para os sistemas de classificação, sistemas de classificação de negócios para gerenciamento de registros, listas de cabeçalhos de assunto, taxonomias, mapas conceituais, redes semânticas, terminologias/banco de termos, listas de autoridades de nomes e anéis de sinônimos. Além disso, traz orientações sobre a prática de mapeamento e de arquitetura. (PROJECT ISO 25964, Tradução nossa).

Ressalta-se a importância dada pelas três normas, não só sobre a questão da interoperabilidade entre vocabulários controlados e da aplicação da análise facetada, mas também no que diz respeito à construção de vocabulários controlados multilíngues, com destaque para os tesauros. Isso nos conduz ao estudo da IFLA intitulado Guidelines for Multilingual Thesauri, realizado em 2009, que apresenta três abordagens para o desenvolvimento de tesauros mulitlingues:

1) Construindo novos tesauros de baixo para cima (bottom up), isto é, do termo específico para o geral:

\footnotetext{
${ }^{6}$ ISO/FDIS 25964-1: Information and documentation -- Thesauri and interoperability with other vocabularies -Part 1: Thesauri for information retrieval http://www.iso.org/iso/iso_catalogue/catalogue_tc/catalogue_detail.htm?csnumber=53657.

${ }^{7}$ ISO/CD 25964-2: Information and documentation -- Thesauri and interoperability with other vocabularies -Part 2: Interoperability with other vocabularies -

http://www.iso.org/iso/iso_catalogue/catalogue_tc/catalogue_detail.htm?csnumber=53658
}

InCID: R. Ci. Inf. e Doc., Ribeirão Preto, v. 2, n. 1, p. 165-192, jan./jun. 2011. 
- começando com uma língua e adicionando outra língua ou línguas;

- começando com mais de uma língua ao mesmo tempo.

2) Combinando tesauros existentes:

- fusão de dois ou mais tesauros existentes na construção de um novo tesauro multilíngue para a indexação e recuperação da informação;

- interligando tesauro e lista de cabeçalho de assunto existente (um com o outro) para uso de ambos na indexação e recuperação da informação;

3) Tradução de um tesauro em uma ou mais línguas.

Sumariamente, o quadro 1 nos mostra as ocorrências principais identificadas em cada uma das normas apresentadas: excluir destaque

\begin{tabular}{|c|c|c|c|}
\hline OCORRÊNCIAS & $\begin{array}{l}\text { ANSI/NISO } \\
\text { Z39:19-2005 }\end{array}$ & BS 8723 & $\begin{array}{c}\text { ISO } 25964 \\
\text { (em desenvolvimento) }\end{array}$ \\
\hline Título & $\begin{array}{l}\text { Guidelines for the } \\
\text { Construction, Format, } \\
\text { and Managment of } \\
\text { Monolingual } \\
\text { Controlled } \\
\text { Vocabularies. }\end{array}$ & $\begin{array}{l}\text { Structured } \\
\text { vocabularies for } \\
\text { information retrieval- } \\
\text { guide. }\end{array}$ & $\begin{array}{l}\text { Information and } \\
\text { documentation -- } \\
\text { Thesauri and } \\
\text { interoperability with } \\
\text { other vocabularies. }\end{array}$ \\
\hline Estrutura & $\begin{array}{l}\text { Onze seções e seis } \\
\text { apêndices: } \\
\text { - ampliação e } \\
\text { atualização da norma } \\
\text { ANSI/NISO Z39:10- } \\
2003 \text {. }\end{array}$ & $\begin{array}{l}\text { Cinco partes: } \\
\text { - a parte } 2 \text { substitui a } \\
\text { norma BS } 5723-1987 \text {; } \\
\text { - a parte } 4 \text { substitui a } \\
\text { norma BS } 6723-1987 \text {. }\end{array}$ & $\begin{array}{l}\text { Duas partes: } \\
\text { - a parte } 1 \text { corresponde } \\
\text { as partes } 1,2 \text { e } 5 \text { da BS } \\
8723 \text {; } \\
\text { - a parte } 2 \text { corresponde } \\
\text { as partes } 3 \text { e } 4 \text { da BS } \\
8723 \text {; } \\
\text { - a ISO } 25964 \text { substitui } \\
\text { as normas ISO } 2788 \text { - } \\
1986 \text { e ISO } 5964 \text { - } \\
1985 \text {. }\end{array}$ \\
\hline Vocabulários controlados & $\begin{array}{l}\text { listas, anéis de } \\
\text { sinônimos, taxonomias, } \\
\text { redes semânticas e } \\
\text { tesauros. }\end{array}$ & $\begin{array}{l}\text { sistemas de } \\
\text { classificação, sistemas } \\
\text { de classificação de } \\
\text { negócios para } \\
\text { gerenciamento de } \\
\text { registros, redes } \\
\text { semânticas, } \\
\text { taxonomias, listas de } \\
\text { cabeçalhos de assunto, } \\
\text { ontologias. }\end{array}$ & 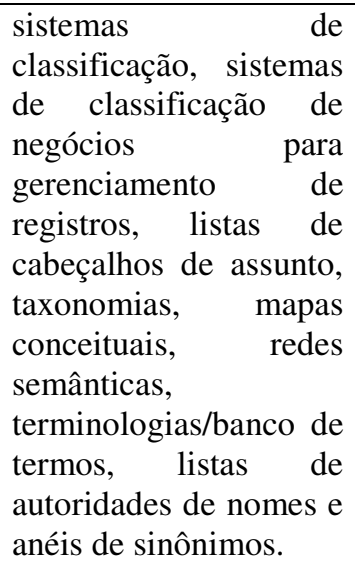 \\
\hline
\end{tabular}




\begin{tabular}{|l|l|l|l|}
\hline Pontos de & -interoperabilidade & -interoperabilidade & -interoperabilidade \\
entre vocabulários \\
entização/ampliação & entre vocabulários & entre vocabulários & controlados; \\
controlados; & -aplicação da análise & -aplicação da análise & -aplicação da análise \\
& facetada na construção & facetada na construção & facetada na construção \\
& de tesauros; & de tesauros; & -vocabulários \\
& -vocabulários & -vocabulários & controlados - \\
& controlados & multilíngues; \\
& multilíngues; & -definição de & -definição de \\
& -definição de & protocolos e formatos & protocolos e formatos \\
& protocolos e formatos & necessários para o \\
& necessários para o & necessários para o & intercâmbio de dados \\
\hline
\end{tabular}

QUADRO 1 - Demonstrativo das ocorrências mais significativas disponíveis nas normas ANSI/NISO Z39.192005, BS 8723 e ISO 25964.

Fonte: Elaboração da autora.

\section{Os Sistemas de Organização do Conhecimento nas perspectivas das normas internacionais de construção}

A norma ANSI/NISO Z39.19-2005 (2005, p. 5) apresenta o conceito de vocabulário controlado correspondendo a uma lista de termos organizados explicitamente em que não podem ser ambíguos e redundantes e devendo ser controlados por uma Autoridade Registrada. O vocabulário controlado abrange diversas estruturas que variam de acordo com os níveis de complexidades envolvidos. São elas: listas de assunto, anéis de sinônimos, taxonomias, redes semânticas e tesauros. (Tradução nossa).

A Norma BS 8723 identifica como vocabulários controlados, além das taxonomias e dos tesauros, os sistemas de classificação, os sistemas de classificação de negócios para gerenciamento de registros, as listas de cabeçalhos de assunto, as redes semânticas e as ontologias. Tal qual as normas ANSI-NISO Z39:10-2005 e BS 8723, a ISO 25964 focaliza as taxonomias, as redes semânticas e os tesauros e acompanhando a BS 8723, destaca, também, os sistemas de classificação, os sistemas de classificação de negócios para gerenciamento de registros, as listas de cabeçalhos de assunto. Além disso, inclui, também, os mapas conceituais, as terminologias/banco de termos e as listas de autoridades de nomes. Tanto quanto a ANSI/NISO Z39:19, apresenta também, os anéis de sinônimos.

Nesse sentido, veem-se atuações e tratamentos diferenciados para os diversos sistemas de organização do conhecimento. Cada um possui características particulares e finalidades distintas que serão sistematizados a partir da classificação de Hodge (2000) e do Networked Knowledge Organization Systems/Services (2010). Esclarece-se que serão definidos e, 
consequentemente, exemplificados somente os sistemas de organização do conhecimento que foram abordados pelos menos por duas normas.

\section{Classificação e Categorização:}

Anéis de Sinônimos (Synonyn rings): conjunto de termos considerados equivalentes para fins de recuperação. Eles são aplicáveis a interfaces de sistemas automatizados de informação no acesso aos conteúdos informacionais que utilizam a linguagem natural como instrumento de recuperação. Exemplo (Figura 1):

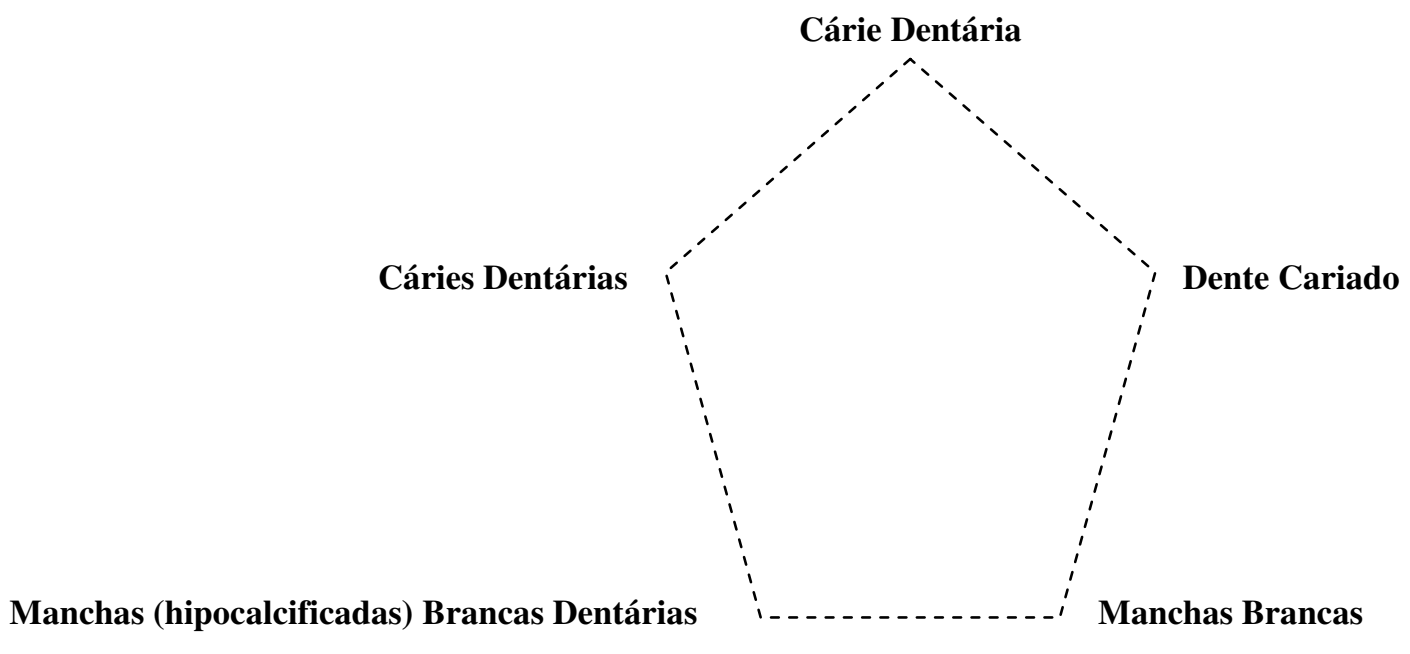

FIGURA 1 - Anéis de sinônimos de cárie dentária na área de Odontologia.

Fonte: Adaptado de ANSI/NISO Z39.19-2005 (2005, p. 18). Terminologia extraída: BIREME. DeCS Descritores em Ciências da Saúde. Disponível em: <http://decs.bvs.br/>. Acesso em: 01 dez. 2011.

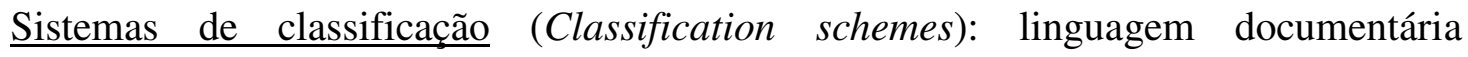
hierárquica, pré-coordenada, formada por signos artificiais que apresentam uma relação de superordenarão e subordinação entre si, em que cada conceito é superior ao conceito seguinte, apresentando-se, dessa maneira, numa estrutura normativa. (BOCCATO, 2008, p. 273). Sua aplicação dá-se, normalmente, para fins de indicar sua localização nas estantes, nos catálogos e nos próprios sistemas de classificação.

Para Guarido (2001, p. 8) os sistemas de classificação configuram-se numa

[...] distribuição sistemática de conceitos em diversas categorias ou classes, de tal maneira, que cada assunto tem um lugar pré-definido. Trata-se de uma linguagem codificada de forma numérica, alfabética ou alfanumérica que pretende ser a descrição sintética do conteúdo dos documentos. Sua utilização é habitual em Unidades de Informação, por seu caráter hierárquico.

InCID: R. Ci. Inf. e Doc., Ribeirão Preto, v. 2, n. 1, p. 165-192, jan./jun. 2011. 
São exemplos de sistemas de classificação o Dewey Decimal Classification (DDC), Universal Decimal Classification (UDC), Library of Congress Classification (LCC), entre outros. Faz-se destaque para a Colon Classification (CC), desenvolvido por Ranganathan, sistema este utilizado em algumas bibliotecas da Índia, do Sudão e do Reino Unido,contribuinte significativamente, entre outros aspectos, no desenvolvimento de tesauros facetados, em que se cita, primeiramente, o Thesaurofacet, publicado em, $1965^{8}$ (8) . Exemplo (Figura 2):

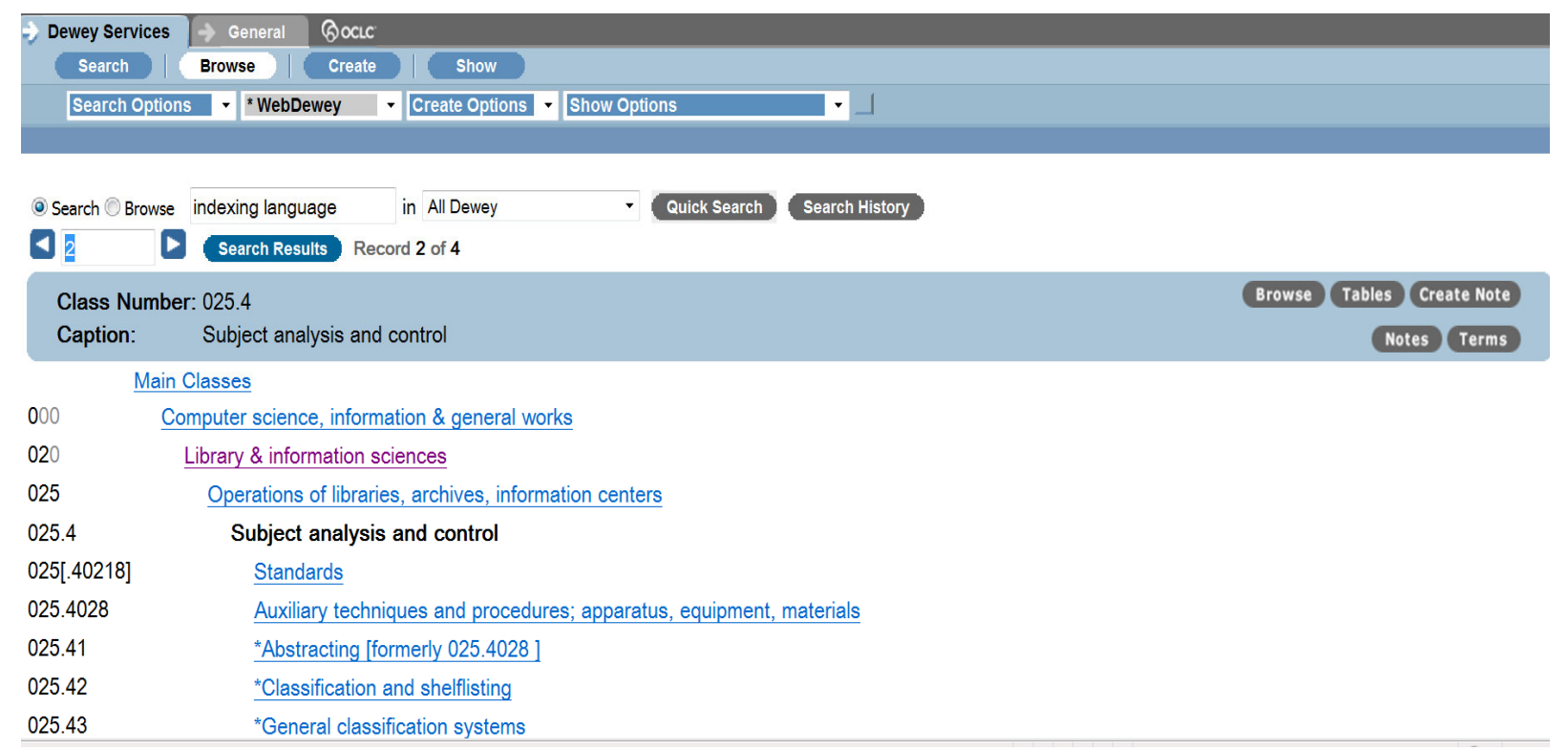

FIGURA 2 - Representação do conceito Subject analysis and control, precedido de sua respectiva notação, acompanhado de sua estrutura hierárquica.

Fonte: WebDewey. Disponível em:

$<$ http://connexion.oclc.org/WebZ/html/corc/corcframe.html?sessionid=cnxs06.prod.oclc.org-37946-glr2bzqlbyxs08:entitydbname=DeweyDB >. Acesso em: 25 mar. 2011. Acesso restrito mediante assinatura.

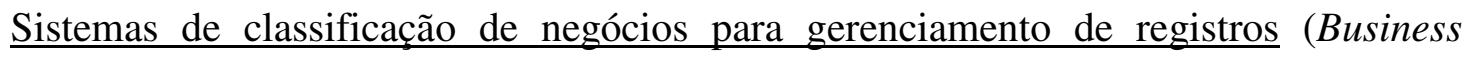
classification schemes for records management): conjunto de termos organizados hierarquicamente, a partir da supeordenação e subordinação existente entre si, para tratar, classificar e controlar informações geradas por uma corporação ${ }^{9}$ para sua recuperação, manutenção, eliminação de registros, entre outras informações corporativas. Existem vários tipos de sistemas de classificação: numérico, cronológico, alfabético (assuntos gerais), tipo do negócio/atividade. (Tradução nossa). Exemplo (Figura 3):

\footnotetext{
${ }^{8}$ AITCHINSON, J. et al. Thesaurofacet: a thesaurus and faceted classification for engineering and related subjects. Leicester: English Electric Co., 1969.

${ }^{9}$ Corporação: "[...] associação de pessoas do mesmo credo ou profissão, sujeitos à mesma regra ou estatutos, e com os mesmos deveres ou direitos; corpo" (FERREIRA, A. B. H. Novo dicionário Aurélio da língua portuguesa. 3. ed. rev. atual. Curitiba: Positivo, 2004. p. 556).
}

InCID: R. Ci. Inf. e Doc., Ribeirão Preto, v. 2, n. 1, p. 165-192, jan./jun. 2011. 


\section{Classification Title \\ Corporate Governance}

- Complaints Management

- Access To Information Complaints Management

- $\quad$ - Service Complaints Management

- . . Stage 1 Complaints Processing

- . . Stage 2 Complaints Processing

- . . Stage 3 Complaints Processing

- $\quad$ - Social Care Complaints Management

- . . Stage 1 Complaints Processing

- . . Stage 2 Complaints Processing

- . . Stage 3 Complaints Processing

- Corporate Legal Services

- Democratic Decision Making

- $\quad$ Committee Meeting Administration

- . Committee Membership Administration

- . Constitution Development \& Review

- $\quad$ Electoral System Support

FIGURA 3 - Sistema de classificação de negócios para gerenciamento de registros por tipo de negócio/atividade do Staffordshire Country Council .

Fonte: STAFFORDSHIRE COUNTRY COUNCIL. Business classification schemes: version 2. Disponível em: $<$ http://www.staffordshire.gov.uk/NR/rdonlyres/1AF03F5E-52A5-4CAB-9B00AFEA617D4FAB/67262/BCSv2.pdf>. Acesso em: 20 mar. 2011.

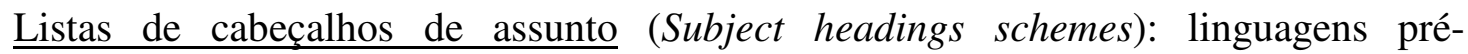
coordenadas, controladas, de estruturas associativa ou combinatória de palavras ou expressões de diversas áreas do conhecimento, cuja finalidade é a de representar para recuperar a informação. "Possuem regras específicas para as formas de entrada dos cabeçalhos e do uso de abreviaturas [...]. (BOCCATO, 2011, p. 15). Exemplo (Figura 4): 


\section{Indexing}

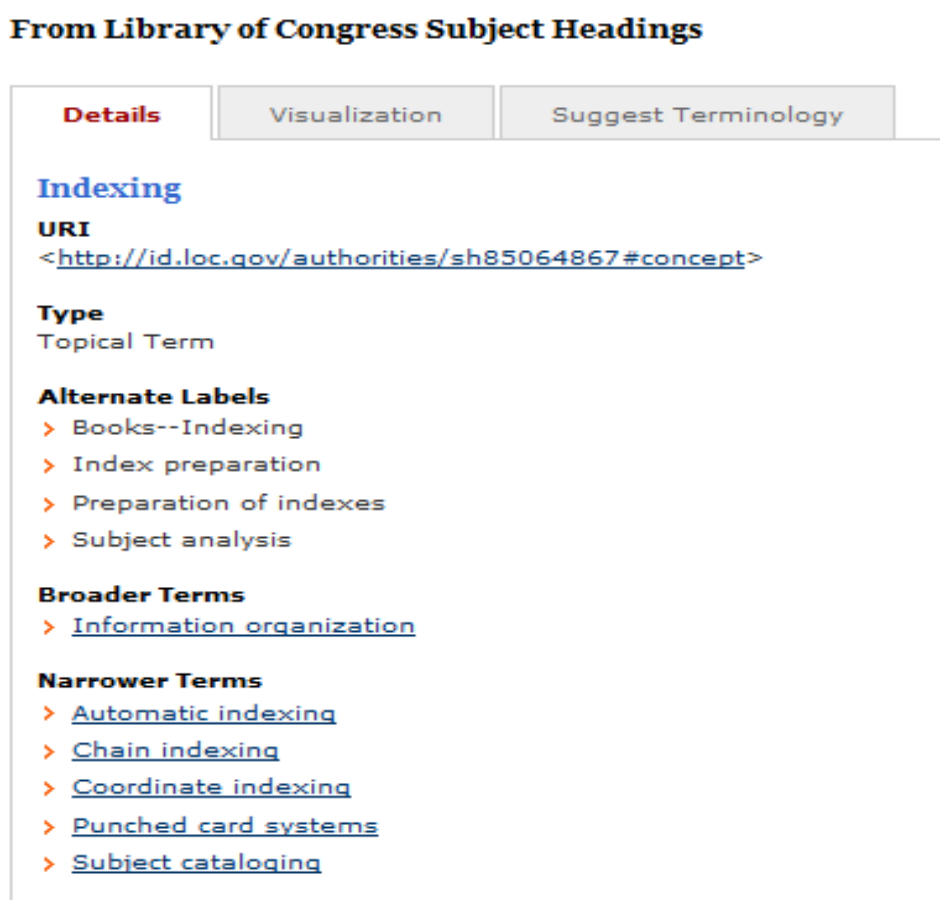

FIGURA 4 - Representação do cabeçalho de assunto Indexing e de sua estrutura relacional.

Fonte: Libray of Congress Subject Headings. Disponível em: <http://id.loc.gov/authorities/sh85064867 >. Acesso em: 25 mar. 2011.

Taxonomias (Taxonomies): vocabulários controlados formados por termos preferenciais, organizados em estruturas hierárquicas ou polihierárquicas. Para Campos e Gomes (2008) elas são

[...] estruturas classificatórias que têm por finalidade servir de instrumento para a organização e recuperação de informação em empresas ${ }^{10}$ e instituições ${ }^{11}$. Estão sendo vistas como meios de acesso atuando como mapas conceituais dos tópicos explorados em um serviço de recuperação. O desenvolvimento de taxonomias para o negócio da empresa tem sido um dos pilares da gestão da informação e do conhecimento.

A norma ANSI-NISO Z39:19 (2005, p. 9) define as taxonomias como um conjunto de termos controlados, organizados em uma estrutura hierárquica. Cada termo em uma taxonomia está em um ou mais relacionamentos genéricos/específicos (broader/narrower) em relação a outros termos na própria taxonomia. (Tradução nossa).

\footnotetext{
${ }^{10}$ Empresa: "organização de negócios, que tem o objetivo de vender produtos e serviços e obter lucros" (MAXIMIANO, A. C. A. Introdução à administração. 7.ed. rev. e ampl. São Paulo: Atlas, 2008. p. 6).

${ }^{11}$ Instituições: "[...] Conjunto de estruturas sociais estabelecidas pela tradição, especialmente as relacionadas com [o sistema] público, [a exemplo das instituições educacionais: escolas, universidades, etc]. (FERREIRA, A. B. H. Novo dicionário Aurélio da língua portuguesa. 3. Ed. Rev. Atual. Curitiba: positivo, 2004. p. 1113).
} 
Currás (2005, p. 60) ressalta que as taxonomias são estruturas conceituais adequadas para uso na Web Semântica. Exemplo (Figura 5):

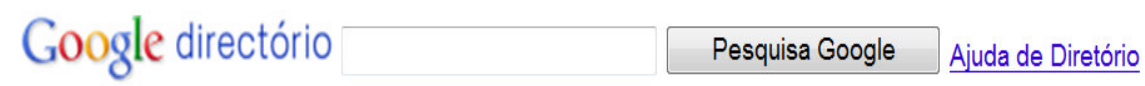

\author{
Ciência e Meio Ambiente \\ Regional > América do Sul > Brasil > Ciência e Meio Ambiente
}

\title{
Categorias
}

\begin{tabular}{|c|c|c|}
\hline Agropecuária (14) & Geologia e Geofísica (2) & Organizações e Institutos (5) \\
\hline Biologia e Biotecnologia (3) & Inteligência Artificial (2) & Química (1) \\
\hline Ciências Sociais (1) & Matemática (6) & Revistas de Meio Ambiente (2) \\
\hline Engenharia (21) & Meio Ambiente (6) & Robótica (2) \\
\hline Física (11) & Oceanografia (2) & $\underline{\text { São Paulo (2) }}$ \\
\hline
\end{tabular}

Geografia (2)

Categoria relacionada:

Ciência (709)

FIGURA 5 - Taxonomia hierárquica de Ciência e Meio Ambiente do Google Directório.

Fonte: Google directório. Disponível em:

$<$ http://www.google.com.br/Top/World/Portugu\%C3\%AAs/Regional/Am\%C3\%A9rica_do_Sul/Brasil/ Ci\%C3\%AAncia_e_Meio_Ambiente/>. Acesso em: 08 mar. 2011.

\section{Modelos de Relacionamentos}

Ontologias (Ontologies): (do grego ontos $=\mathrm{ser}+\log o s=$ palavra $)$. Gruber $(1993, \mathrm{p}$. 139) define as ontologias como [...] uma especificação de uma conceitualização [...]”, isto é, são sistemas de organização do conhecimento que permitem organizar, classificar, recuperar, compartilhar e reutilizar informações em ambientes digitais.

Tal qual os tesauros, as ontologias também são constituídas por

[...] um conjunto de termos estruturados hierarquicamente, formando uma estrutura de classes e subclasses. As classes de uma ontologia representam as entidades ${ }^{12}$ do 'mundo real', que são agrupadas e categorizadas de acordo com suas similaridades, levando-se em consideração um domínio concreto. (BOCCATO, RAMALHO, FUJITA, 2008, p. 203).

Sales (2007) aborda sobre as relações conceituais encontradas nas ontologias, classificando-as em relações categoriais e relações formais. A primeira refere-se às relações que retratam duplas de categorias, ex: coisa/processo, material/produto, entre outras. A segunda diz respeito à relação existente entre essas duplas de categorias, ex: "causado por";

\footnotetext{
${ }^{12}$ Para Boccato, Ramalho e Fujita (2008, p. 203), “[...] entidades podem representar coisas físicas ou conceituais, desde objetos inanimados até teorias científicas ou correntes teóricas, de modo que uma classe pode possuir diversas subclasses, que podem organizar as entidades a partir de características mais específicas".
}

InCID: R. Ci. Inf. e Doc., Ribeirão Preto, v. 2, n. 1, p. 165-192, jan./jun. 2011. 
“ocorrido em", etc. As ontologias não apresentam sempre as mesmas estruturas, porém os seus componentes básicos, além dos conceitos, das classes e das relações, são também as funções, os axiomas e as instâncias. Exemplo (Figura 6):

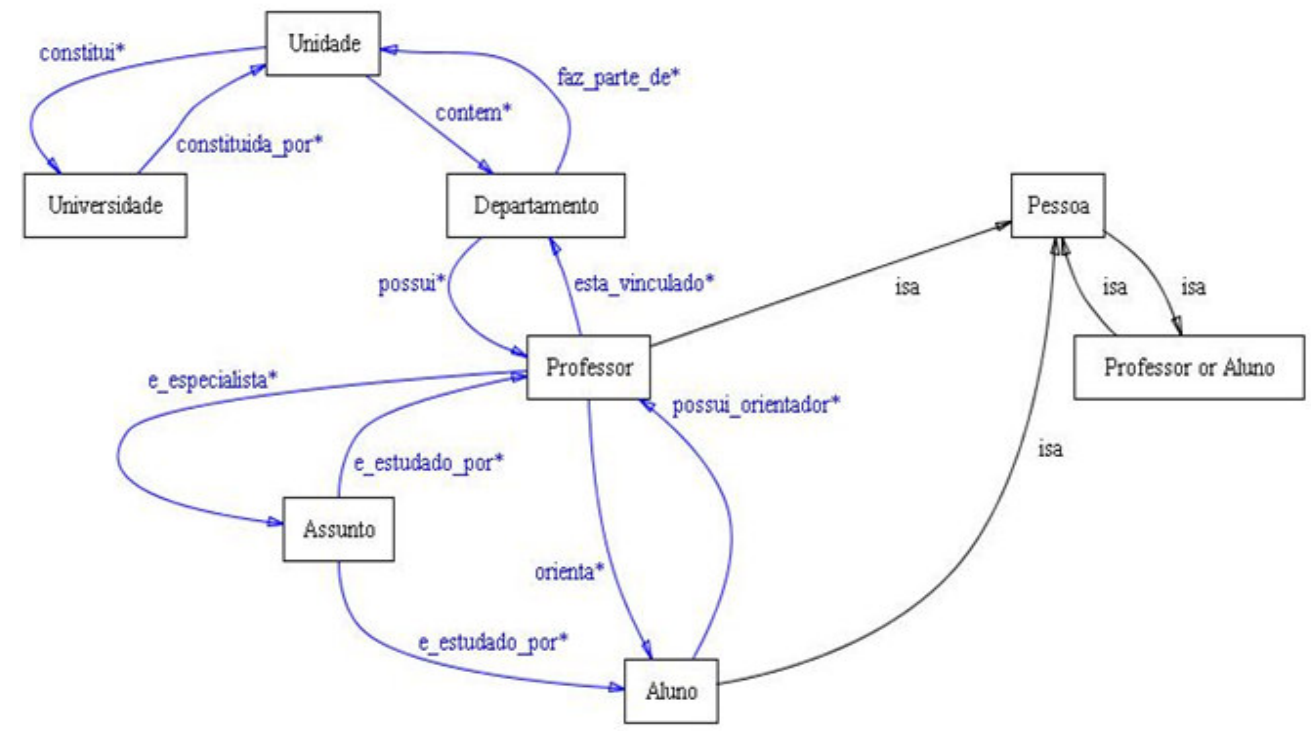

FIGURA 6 - Diagrama de parte de ontologia de um domínio acadêmico ${ }^{13}$.

Fonte: BOCCATO; RAMALHO; FUJITA (2008, p. 206).

Redes semânticas (Semantic networks): conjunto de termos que representam conceitos, modelados a partir de uma notação gráfica composta por nodos interconectados. As redes semânticas podem ser utilizadas para a representação do conhecimento ou como ferramenta de apoio para sistemas automatizados de inferências sobre o conhecimento. As redes semânticas podem ser divididas em: redes de definição; redes de asserção; redes de implicação; redes executáveis; redes de aprendizado; redes híbridas. (SOWA, 2011).

A figura 7 mostra parte de uma rede semântica da Unified Medical Language System (UMSL), produzida pela National Library of Medicine (Estados Unidos), considerada como uma "rede semântica de definição", apresentando um método de categorização a partir de uma estrutura hierárquica de tipos e subtipos. Esse modelo de rede semântica evidencia a relação hierárquica de gênero/espécie encontrada, por exemplo, nos tesauros.

\footnotetext{
${ }^{13}$ Na Figura 6 vê-se uma parte de ontologia de um domínio acadêmico desenvolvida com o uso do programa Protégé. O "isa" é um conector gerado pelo próprio programa que significa "é um" (em inglês "is a"). Exemplo: Professor isa Pessoa - Professor é uma Pessoa.
} 


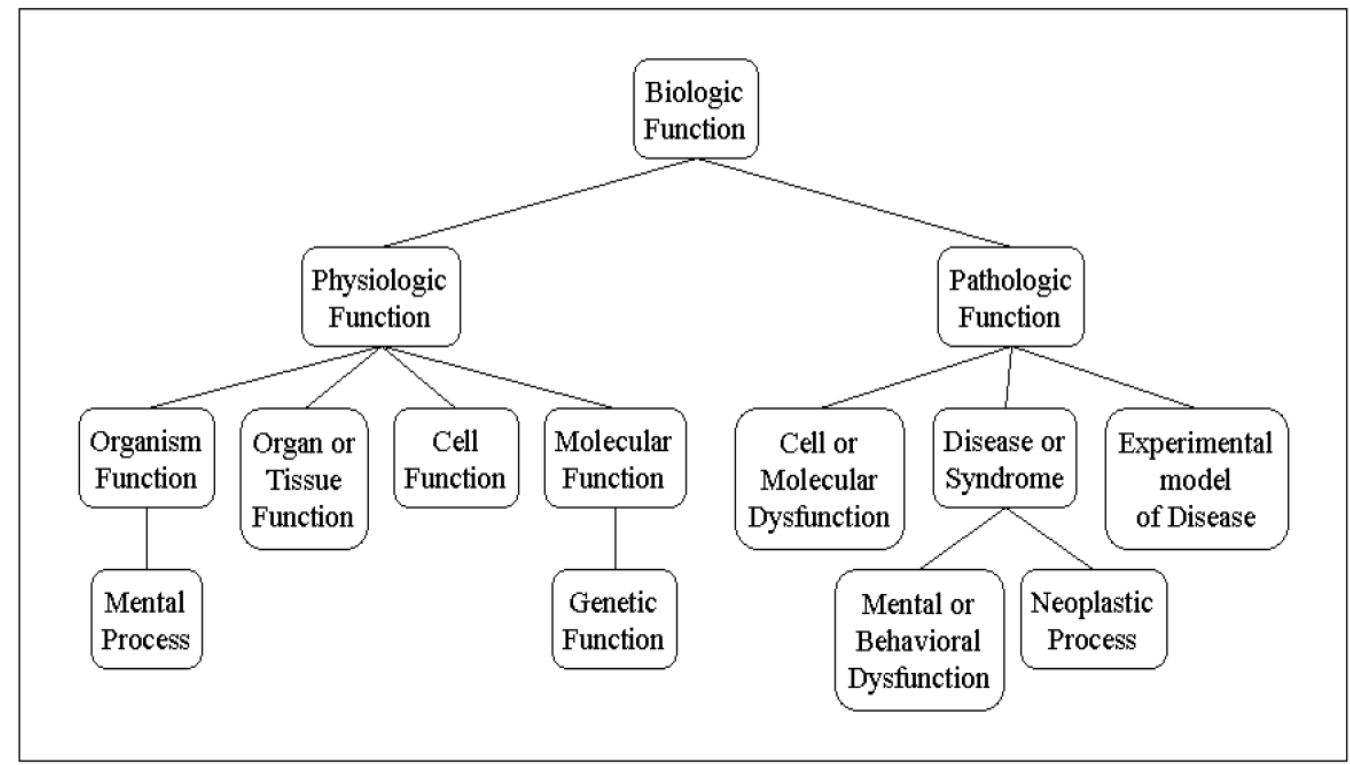

FIGURA 7 - Rede semântica de definição: parte da rede semântica da UMSL.

Fonte: UNIFIED MEDICAL LANGUAGE SYSTEM (UMLS) Documentation, Section 3, UMLS Semantic Network.16th Release, 2004AB. Bethesda (MD): U.S. National Library of Medicine; [2004?]. Disponível em: <http://www.nlm.nih.gov/research/umls/meta3.html>. Acesso em: 19 mar. 2011.

Tesauros (Thesaurus): sistemas de organização do conhecimento que permitem a organização de termos descritores a partir de relações lógico-semânticas de ordens hierárquicas, equivalentes e associativas.

Sobre isso, Gardin et al. (1968 apud Cintra, 2002, p. 35-36), expõe que uma linguagem documentária deve integrar três elementos básicos:

- um léxico, identificado como uma lista de elementos descritores,

- devidamente filtrados e depurados;

- uma rede paradigmática para traduzir certas relações essenciais e, geralmente estáveis, entre descritores; e

- uma rede sintagmática destinada a expressar as relações contingentes entre os descritores, relações que são válidas no contexto particular onde aparecem.

A ANSI-NISO Z39:19 (2005, p. 9) caracteriza os tesauros como um vocabulário controlado organizado em uma ordem conhecida e estruturada de modo que os vários relacionamentos entre os termos sejam identificados e indicados claramente por meio de orientações normativas. (Tradução nossa).

Para Boccato, Ramalho e Fujita (2008, p. 201), os tesauros são 
linguagens de estruturas combinatórias e pós-coordenadas, constituídas de termos unidades linguísticas provenientes da linguagem de especialidade e da linguagem natural, denominados de descritores, providos de relações sintático-semânticas, referentes a domínios científicos especializados, possibilitando a representação temática do conteúdo de um documento, bem como a recuperação da informação.

Os tesauros são formados por estruturas conceituais complexas de relações semânticas que permitem ao usuário acessar e associar conceitos a partir de descritores que possam representam sua necessidade de informação. As estruturas caracterizadas nos tesauros só permitem a recuperação de documentos que possuem tais relações descritas em seu contexto inicial de representação (corpus de análise). Ressalta-se que o incremento das relações de equivalência e associativas no repertório terminológico possibilita maior aproximação entre o tesauro e a linguagem de busca do usuário, condição essa de suma importância para o adequado desempenho do instrumento terminológico em sistemas automatizados de informação. Exemplo (Figura 8):

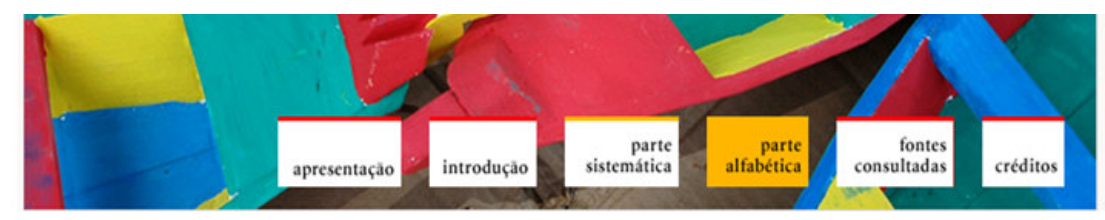

BBoco

Cordão formado por foliões, em geral vestindo fantasias iguais e cantando seu hino, que desfila pelas ruas durante os dias de carnaval, acompanhado por banda de música. Em Recife o desfile de blocos costuma ser aberto por um cartaz que anuncia o nome e o símbolo do grupo, e é seguido pela diretoria, depois da qual vêm damas-de-frente, fantasias de destaque, cordão de homens e mulheres, coral de vozes e orquestra. Geralmente o bloco traz enredo em seu conjunto de fantasias, mas a composição entoada não tem necessariamente relação com o tema das fantasias.

Usado por

- Banda (folguedo)

Termo Genérico

- Cordão

Termos Específicos

- Bloco de sujo

- Cai n'água

- Cobra jararaca

- Negras da costa

- Urso do carnaval

Termos Associados

- Clube de frevo

- $\underline{\text { Folião }}$

FIGURA 8 - Representação do descritor Bloco e de suas relações lógico-semânticas.

Fonte: TESAURO de Folclore e Cultura Popular Brasileira. Disponível em: <http://www.cnfcp.gov.br/tesauro/00002006.htm>. Acesso em: 23 jan. 2011.

InCID: R. Ci. Inf. e Doc., Ribeirão Preto, v. 2, n. 1, p. 165-192, jan./jun. 2011. 
No contexto da internet e tendo em vista a organização da Web Semântica, presenciase a evolução dos tesauros a partir do uso de linguagens de marcação, como o $X M L$ (eXtensible Markuk Language), na construção de tesauros navegáveis, permitindo a migração de tesauros tradicionais a formatos inteligíveis por máquinas, que propicia o intercâmbio e a interoperabilidade entre sistemas de organização do conhecimento. O SKOS-Core (Simple Knowledge Organization System), iniciativa do World Wide Web Consortium (W3C) é um esquema suportado no RDF (Resource Description Framework) que atende tais finalidades, a partir do desenvolvimento de especificações e normas que proporcionam um modelo para representar a estrutura conceitual básica e o conteúdo de sistemas de organização do conhecimento, tais como os tesauros, sistemas de classificação, listas de cabeçalhos de assunto, taxonomias e outros vocabulários controlados similares na Web Semântica. (SKOS, 2011, GRUPO DE TRABAJO DEL W3, 2010, p. 286. Tradução nossa).

Vale ressaltar a presença das folksonomias, embora não arrolada pelas três normas internacionais, como um sistema social de organização do conhecimento aplicável, também no contexto da internet.

Para Wal (2006), as "folksonomias" (do inglês: folks= pessoas + taxonomy = taxonomia) são os resultados das marcações (atribuições) livres e pessoais de etiquetas (tags) a informações ou objetos (qualquer coisa com URL- Uniform Resource Locator), tendo em vista a sua recuperação. Essa indexação social prevê a participação do usuário mediante o uso da linguagem natural, isto é, a linguagem expressa por ele para a representação, busca e recuperação em ambientes informacionais colaborativos. O usuário é o ator principal e integrante ativo em que a sua percepção e a sua opinião são pressupostos referenciais para a efetivação desses processos. São exemplos de algumas iniciativas: Flickr, Del.icio.us, YouTube, 43 things. (Figura 9). 


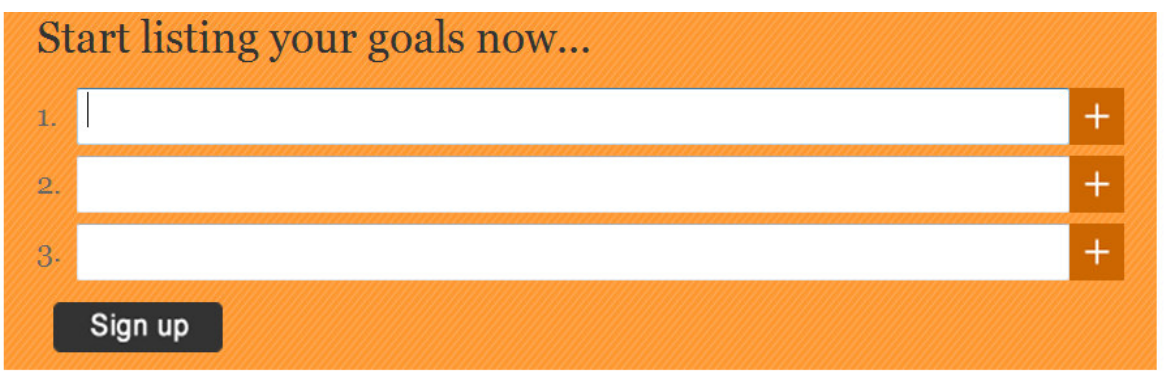

43 Things is the world's largest goal-setting community. People here want to:

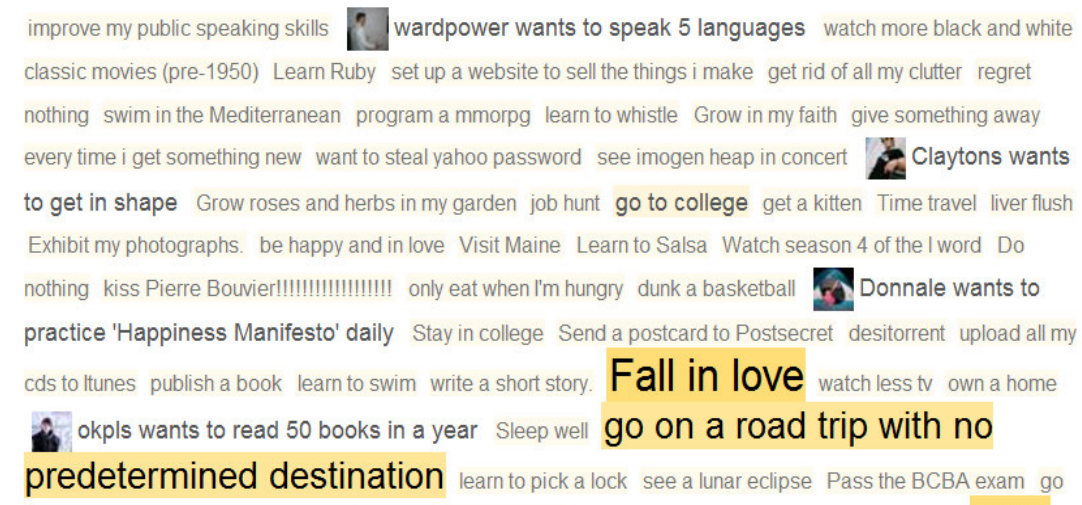

to the oscars Get my laundry done sleep under the stars make more true friends be my own boss Stop

procrastinatina rezilla wants to become a quitar hero lose 20 lbs let qo be more

FIGURA 9 - Formulário de entrada e apresentação de etiquetas (tags) do 43Things.

Fonte: 43Thing. Disponível em: <http://www.43things.com/>. Acesso em: 06 mar. 2011.

Em síntese, o quadro 2 apresenta uma sumarização dos sistemas de organização do conhecimento e seus aspectos quanto à finalidade, estrutura/tipos de relacionamentos entre conceitos, contexto de aplicação, tipos de usuários e normas, focalizados pela ANSI/NISO Z39:19-2005, BS 8723 e ISO 25964:

\begin{tabular}{|l|l|l|l|l|l|}
\hline OCORRÊNCIAS & FINALIDADE & \multicolumn{1}{|c|}{$\begin{array}{c}\text { ESTRUTURA/ } \\
\text { RELACIONAMENTOS }\end{array}$} & $\begin{array}{c}\text { CONTEXTO } \\
\text { DE } \\
\text { APLICAÇÃo }\end{array}$ & USUÁRIOS & NORMAS \\
\hline $\begin{array}{l}\text { Anéis de } \\
\text { sinônimos }\end{array}$ & $\begin{array}{l}\text { controlar os } \\
\text { termos } \\
\text { sinônimos em } \\
\text { interfaces de } \\
\text { sistemas } \\
\text { automatizados } \\
\text { de informação } \\
\text { que } \\
\text { utilizam a } \\
\text { linguagem } \\
\text { natural como } \\
\text { instrumento de } \\
\text { recuperação }\end{array}$ & $\begin{array}{l}\text { controle de sinônimos } \\
\text { equivalências } \\
\text { automatizados } \\
\text { de informação }\end{array}$ & $\begin{array}{l}\text { usuários } \\
\text { especialistas não } \\
\text { ou }\end{array}$ & $\begin{array}{l}\text { ANSI/NISO } \\
\text { Z39:19-2005 } \\
\text { ISO 25964 }\end{array}$ & \\
\\
\hline
\end{tabular}

QUADRO 2 - Sistemas de organização do conhecimento e seus aspectos pelas perspectivas das normas internacionais de construção.

Fonte: Elaboração da autora. 


\begin{tabular}{|c|c|c|c|c|c|}
\hline OCORRÊNCIAS & FINALIDADE & $\begin{array}{l}\text { ESTRUTURA/ } \\
\text { RELACIONAMENTOS }\end{array}$ & $\begin{array}{l}\text { CONTEXTO } \\
\text { DE } \\
\text { APLICAÇÃO }\end{array}$ & USUÁRIOS & NORMAS \\
\hline $\begin{array}{l}\text { Sistemas de } \\
\text { classificação }\end{array}$ & $\begin{array}{l}\text { classificar para } \\
\text { recuperar a } \\
\text { informação, } \\
\text { com visas a } \\
\text { localização do } \\
\text { material }\end{array}$ & $\begin{array}{l}\text { controle de ambiguidade } \\
\text { controle de sinônimos } \\
\text { r elacionamentos } \\
\text { hierárquicos }\end{array}$ & $\begin{array}{l}\text { unidades de } \\
\text { informação }\end{array}$ & $\begin{array}{l}\text { usuários } \\
\text { especialistas } \\
\text { ou não }\end{array}$ & $\begin{array}{l}-- \\
\text { BS } 8723 \\
\text { ISO } 25964\end{array}$ \\
\hline $\begin{array}{l}\text { Sistemas de } \\
\text { classificação de } \\
\text { negócios para } \\
\text { gerenciamento de } \\
\text { registros }\end{array}$ & $\begin{array}{l}\text { classificar para } \\
\text { recuperar, } \\
\text { manter e } \\
\text { eliminar } \\
\text { registros, entre } \\
\text { outras } \\
\text { informações } \\
\text { corporativas } \\
\end{array}$ & $\begin{array}{l}\text { controle de ambiguidade } \\
\text { controle de sinônimos } \\
\text { r elacionamentos } \\
\text { hierárquicos }\end{array}$ & $\begin{array}{l}\text { ambientes } \\
\text { informacionais } \\
\text { na web } \\
\text { (Instituições/ } \\
\text { Corporações, } \\
\text { etc.) }\end{array}$ & $\begin{array}{l}\text { usuários da } \\
\text { web }\end{array}$ & $\begin{array}{l}--- \\
\text { BS } 8723 \\
\text { ISO } 25964\end{array}$ \\
\hline $\begin{array}{l}\text { Listas de } \\
\text { cabeçalhos de } \\
\text { assunto }\end{array}$ & $\begin{array}{l}\text { organizar, } \\
\text { categorizar para } \\
\text { recuperar a } \\
\text { informação }\end{array}$ & $\begin{array}{l}\text { controle de ambiguidade } \\
\text { controle de sinônimos } \\
\text { r elacionamentos } \\
\text { hierárquicos } \\
\text { relacionamentos de } \\
\text { equivalências } \\
\text { r elacionamentos } \\
\text { associativos }\end{array}$ & $\begin{array}{l}\text { sistema de } \\
\text { informação }\end{array}$ & $\begin{array}{l}\text { usuários } \\
\text { especialistas } \\
\text { ou não }\end{array}$ & $\begin{array}{l}-- \\
\text { BS } 8723 \\
\text { ISO } 25964\end{array}$ \\
\hline Taxonomias & $\begin{array}{l}\text { classificar, } \\
\text { categorizar e } \\
\text { apresentar para } \\
\text { recuperar a } \\
\text { informação }\end{array}$ & $\begin{array}{l}\text { controle de ambiguidade } \\
\text { controle de sinônimos } \\
\text { r elacionamentos } \\
\text { hierárquicos }\end{array}$ & $\begin{array}{l}\text { ambientes } \\
\text { informacionais } \\
\text { na web } \\
\text { (Empresas, etc.) }\end{array}$ & $\begin{array}{l}\text { usuários da } \\
\text { web }\end{array}$ & $\begin{array}{l}\text { ANSI/NISO } \\
\text { Z39:19-2005 } \\
\text { BS } 8723 \\
\text { ISO } 25964\end{array}$ \\
\hline Ontologias & $\begin{array}{l}\text { organizar, } \\
\text { categorizar para } \\
\text { recuperar a } \\
\text { informação }\end{array}$ & $\begin{array}{l}\text { controle de ambiguidade } \\
\text { controle de sinônimos } \\
\mathrm{r} \text { elacionamentos } \\
\text { hierárquicos } \\
\text { r elacionamentos de } \\
\text { instâncias } \\
\text { relacionamentos de } \\
\text { equivalências } \\
\text { r elacionamentos } \\
\text { associativos } \\
\text { a presentação de } \\
\text { propriedades }\end{array}$ & $\begin{array}{l}\text { ambientes } \\
\text { informacionais } \\
\text { digitais na web } \\
\text { (repositórios, } \\
\text { bibliotecas } \\
\text { digitais, } \\
\text { comércio } \\
\text { eletrônico, etc.) }\end{array}$ & $\begin{array}{l}\text { usuários } \\
\text { especialistas } \\
\text { ou não da web }\end{array}$ & $\begin{array}{l}-- \\
\text { BS } 8723 \\
\text { ISO } 25964\end{array}$ \\
\hline Redes semânticas & $\begin{array}{l}\mathrm{r} \text { epresentar o } \\
\text { conhecimento } \\
\text { ou servir como } \\
\text { ferramenta de } \\
\text { apoio para } \\
\text { sistemas } \\
\text { automatizados } \\
\text { de inferências } \\
\text { sobre o } \\
\text { conhecimento }\end{array}$ & $\begin{array}{l}\text { controle de ambiguidade } \\
\text { controle de sinônimos e } \\
\text { antônimos } \\
\mathrm{r} \text { elacionamentos } \\
\text { hierárquicos } \\
\text { relacionamentos de } \\
\text { equivalências } \\
\mathrm{r} \text { elacionamentos de } \\
\text { instâncias } \\
\mathrm{r} \text { elacionamentos } \\
\text { associativos }\end{array}$ & $\begin{array}{l}\text { ambientes } \\
\text { informacionais } \\
\text { digitais na } w e b\end{array}$ & $\begin{array}{l}\text { usuários } \\
\text { especialistas } \\
\text { ou não da web }\end{array}$ & $\begin{array}{l}\text { ANSI/NISO } \\
\text { Z39:19-2005 } \\
\text { BS } 8723 \\
\text { ISO } 25964\end{array}$ \\
\hline
\end{tabular}




\begin{tabular}{|c|c|c|c|c|c|}
\hline Tesauros & $\begin{array}{l}\text { organizar, } \\
\text { categorizar para } \\
\text { recuperar a } \\
\text { informação }\end{array}$ & $\begin{array}{l}\text { controle de ambiguidade } \\
\text { controle de sinônimos } \\
\text { relacionamentos } \\
\text { hierárquicos } \\
\text { relacionamentos de } \\
\text { equivalências } \\
\text { relacionamentos } \\
\text { associativos }\end{array}$ & $\begin{array}{l}\text { sistemas de } \\
\text { informação } \\
\text { especializados } \\
\text { (bases de dados, } \\
\text { catálogos on- } \\
\text { line, etc.) }\end{array}$ & $\begin{array}{l}\text { usuários } \\
\text { especialistas } \\
\text { de sistemas de } \\
\text { informação }\end{array}$ & $\begin{array}{l}\text { ANSI/NISO } \\
\text { Z39:19-2005 } \\
\text { BS } 8723 \\
\text { ISO } 25964\end{array}$ \\
\hline
\end{tabular}

QUADRO 2 - Sistemas de organização do conhecimento e seus aspectos nas perspectivas das normas internacionais de construção.

Fonte: Elaboração da autora.

\section{Considerações finais}

O objetivo deste estudo foi apresentar os conceitos, as funções e as características dos sistemas de organização do conhecimento disponíveis na contemporaneidade, especificando suas particularidades e generalizando suas aplicações nos mais diversos contextos de uso, pelas perspectivas das normas internacionais (standards) para a Organização e Recuperação da Informação em Ciência da Informação. $O$ universo de pesquisa foram as normas internacionais ANSI/NISO Z39.19-2005, BS 8723 e ISO 25964, com a apresentação de seus históricos e apontando, também, as expansões e atualizações mais significativas ocorridas entre elas.

O cenário apresentado pela literatura técnica (normas internacionais) nos mostra as Tecnologias de Informação e Comunicação como ferramentas colaborativas na modelagem de tesauros, no desenvolvimento de sistemas de gestão de vocabulários controlados e na realização da interoperabilidade entre vocabulários controlados como um recurso de construção. Essas possibilidades, dentre outras apresentadas pelas normas nos conduz ao desenvolvimento de sistemas de organização do conhecimento capazes de atender, cada vez mais, as necessidades de buscas de diferentes usuários locais e remotos, a partir do acesso fácil, ágil e interativo às informações disponíveis em qualquer suporte e espaço informacional.

No contexto das normas internacionais, tal realidade é perceptível e associada às diretrizes que estabelecem orientações na modelagem de sistemas de organização do conhecimento com rigor terminológico e consistência nas estruturas relacionais, promovem instrumentos compatíveis com as necessidades dos leitores (profissionais/indexadores e usuários) que permitem representar para recuperar os recursos informacionais almejados.

InCID: R. Ci. Inf. e Doc., Ribeirão Preto, v. 2, n. 1, p. 165-192, jan./jun. 2011. 
Os sistemas de organização do conhecimento elaborados a partir de diretrizes normativas que acompanham o desenvolvimento informacional e tecnológico são considerados importantes instrumentos de representação e recuperação em sistemas de informação e em ambientes digitais e em redes sociais de comunicação, na web.

A nova web (web 2.0) despertou o interesse da comunidade científica para o desenvolvimento de pesquisas sobre sistemas de organização do conhecimento aplicáveis em meios digitais, visando à construção de bases teóricas e metodológicas que consolidem essa vertente de estudo ainda pouco explorada.

Essa perspectiva teórica nos faz pensar sobre a necessária intensificação no desenvolvimento de estudos que valorizam a interdisciplinaridade da área de Ciência da Informação com outras ciências na compreensão, organização e representação da informação nesse universo digital. Essa postura científica contemporânea é de vital importância no cumprimento do papel social que a área de Ciência da Informação possui.

Todavia, no contexto atual da prática profissional, encontra-se, também um cenário diferenciado, porém norteado por uma convivência "pacífica" entre os recursos informacionais impressos e eletrônicos influenciando novas condutas gerenciais e de profissionais da informação atuantes em vários espaços de informação. Tal convivência - de um recurso com/para o outro, aliás, compreensível dentro de uma escala evolutiva tecnológica que aprimora os meios de acessos informacionais, proporciona-nos, cada vez mais, o acesso e a recuperação ilimitada da informação em sistemas de recuperação automatizados e no ambiente web.

Acredita-se que tanto os "tradicionais" (impressos) como os "modernos" (eletrônicos) recursos de informação continuarão a serem utilizados e naturalmente construídos, sem que se extingam diante dessas novas tecnologias de informação.

A norma ANSI-NISO Z39:19-2005 traz orientações fundamentais na construção, formatos de apresentação e gestão de vocabulários controlados, porém não considera os demais sistemas de organização do conhecimento existentes na atualidade - ontologias, mapas conceituais, rede semânticas, entre outros - para a organização e recuperação de recursos disponibilizados na web. Por sua vez, a BS 8723 e a ISO 25964 abrangem diferentes tipos de vocabulários, desde os sistemas de classificação até os variados instrumentos de representação de recursos informacionais, também na web.

InCID: R. Ci. Inf. e Doc., Ribeirão Preto, v. 2, n. 1, p. 165-192, jan./jun. 2011. 
Nessa perspectiva, faz-se necessário a atualização contínua das normas internacionais de construção, formato e gerenciamento de vocabulários controlados para que estas possam constituir-se em instrumentos diretivos e norteadores na construção de sistemas de organização do conhecimento adequados para distintas unidades e ambientes informacionais que disponibilizam diversificados recursos de informação para a recuperação condizente com as necessidades de informação de profissionais e usuários especialistas ou não.

\section{Referências}

ANSI/NISO Z39.19-2003: guidelines for the construction, format, and management of monolingual thesauri. Bethesda: NISO, 2003.

ANSI/NISO Z39.19-2005: guidelines for the construction, format, and management of monolingual controlled vocabularies. Bethesda: NISO, 2005. 172 p. Disponível em: $<$ http://www.niso.org/kst/reports/standards/kfile_download?id\%3Austring\%3Aiso-88591=Z39-19-2005.pdf\&pt=RkGKiXzW643YeUaYUqZ1BFwDhIG424RJbcZBWg8uE4vWdpZsJDs4RjLz0t90_d5_ymGsj_IKVaGZww13HuDIYn5U74YdfA3TffjxYQ25QrtR8PONuJLqxvo-10NIr5>. Acesso em: 30 jan. 2011.

BOCCATO, V. R. C. A linguagem documentária como instrumento de organização e recuperação da informação. In: HOFFMANN, W. A. M.; FURNIVAL, A. C. (Org.). Olhar: ciência, tecnologia e sociedade. São Carlos: Pedro e João Ed., CECH-UFSCar, 2008. p. 269278.

BOCCATO, V. R. C. Linguagem documentária na representação e recuperação da informação pela perspectiva sociocognitiva em ciência da informação. In: BOCCATO, V. R. C.;

GRACIOSO, L. de S. Estudos de linguagem em ciência da informação. Campinas: Alínea, 2011. p. 9-34.

BOCCATO, V. R. C.; RAMALHO, R. A. S; FUJITA, M. S. L. A contribuição dos tesauros na construção de ontologias como instrumento de organização e recuperação da informação em ambientes digitais. In: GARÍA MARCO, F. J. Avances y perspectivas en sistemas de información y documentación - IBERSID 2008. Zaragoza: Universidad de Zaragoza, 2008. p. 199-209. Disponível em: <http://www.ibersid.org/>. Acesso em: 12 dez. 2010.

BS 5723-1987: guidelines for the establishment and development of monolingual thesauri. London: The British Standards Institute, 1987.

BS 6723-1985: guidelines for the establishment and development of multilingual thesauri. London: The British Standards Institute, 1985.

BS 8723-1:2005: structured vocabularies for information retrieval: guide,definitions, symbols and abbreviations. London: British Standards Institution, 2005. 
BS 8723-2:2005: structured vocabularies for information retrieval: guide: thesauri. London: British Standards Institution, 2005.

BS 8723-3:2007: structured vocabularies for information retrieval: guide: vocabularies other than thesauri. London: British Standards Institution, 2007.

BS 8723-4:2007: structured vocabularies for information retrieval: guide: interoperability between vocabularies. London: British Standards Institution, 2007.

BS 8723-5:2008: structured vocabularies for information retrieval: guide: interoperation between vocabularies and other components of information storage and retrieval systems. London: British Standards Institution, 2008.

CAMPOS, M. L. de A.; Gomes, H. E. Taxonomia e classificação: o princípio de categorização. DataGramaZero - Revista de Ciência da Informação, Rio de Janeiro, v. 9, n. 4. Ago. 2008. Disponível em: <http://www.dgz.org.br/ago08/Art_01.htm>. Acesso em: 06 mar. 2011.

CASSAR, M. Organizações, administração e suas teorias. In: DIAS, R.; ZAVAGLIA, T.; CASSAR, M. Introdução à administração: da competitividade à sustentabilidade.

Campinas: Alínea, 2003. p.12-111.

CINTRA, A. M. M. et al. Para entender as linguagens documentárias. 2. ed. rev. e ampl. São Paulo: Polis, 2002.

CURRÁS, E. Ontologías, taxonomias y tesauros: manual de construcción y uso. 3. ed. actual. y ampl. Gijón: Trea, 2005.

DAVENPORT, Thomas H. Ecologia da informação. São Paulo: Futura, 2001.

GARDIN, J.-C. et al. L'automatisation des recherches documentaires: un modèle général «Le SYNTOL ». 2. ed. Revue et augmentée. Paris: Gauthier-Villars, 1968.

GRUBER, T. A translating approach to portable ontology specifications. Knowledge Acquisition, London, v. 5, n. 2, p. 199-220, 1993.

GRUPO DE TRABAJO DEL W3. Manual de SKOS: Simple Knowledge Organization System= Sistema para la Organización del Conocimiento Simple. Anales de Documentación, Múrcia, v. 13, p. 285-320, 2010. Disponível em: <http://revistas.um.es/analesdoc/article/view/107511/102161>. Acesso em: 17 jan. 2011.

GUARIDO, M. D. M. Como usar e aplicar a CDD 22ª edição. Marília: FUNDEPE; São Paulo: CGB-UNESP, 2008.

HODGE, G. Systems of knowledge organization for digital libraries: beyond traditional authority files. Washington: The Digital Library Federation, The Council on Library and Information Resources, 2000. Disponível em: <http://www.clir.org/pubs/abstract/pub91abst.html> . Acesso em: 08 fev. 2011. 
IFLA. Guidelines for multilingual thesauri. The Hague, IFLA Headquarters, 2009. Disponível em: < http://archive.ifla.org/VII/s29/pubs/Profrep115.pdf > . Acesso em: 08 mar. 2011.

ISO 5964:1985: documentation: guidelines for the establishment and development of multilingual thesauri. Geneva: ISO, 1986.

ISO 2788:1986: documentation: guidelines for the establishment and development of monolingual thesauri. Geneva: ISO, 1986.

NETWORKED KNOWLEDGE ORGANIZATION SYSTEMS/SERVICES. NKOS. Disponível em:

<http://nkos.slis.kent.edu/>. Acesso em: 07 fev. 2011.

PROJECT ISO 25964: thesauri and Interoperability with other vocabularies. Disponível em: <http://www.niso.org/workrooms/iso25964>. Acesso em: 04 fev. 2011.

SALES, L. F. relações conceituais para instrumentos de padronização terminológica: um novo modelo para o uso em Ontologias. In: ENCONTRO NACIONAL DE PESQUISA EM CIÊNCIA DA INFORMAÇÃO, 8.,2007, Salvador. Anais... Salvador: UFBa, 2007. Diponível em: <http://www.enancib.ppgci.ufba.br/artigos/GT2--088.pdf> $>$. Acesso em: 25 fev. 2011.

SKOS - Simple Knowledge Organization System. Disponível em:

<http://www.w3.org/2004/02/skos/>. Acesso em: 06 mar. 2011.

SOWA, J. F. Semantic networks. Disponível em < http://www.jfsowa.com/pubs/semnet.htm > Acesso em: 20 mar. 2011.

TAPARANOFF, K.; ARAÚJO JÚNIOR, R. H. de; CORMIER, P. M. J. Sociedade da informação e inteligência em unidades de informação. Ciência da Informação, Brasília, v. 29, n. 3, p. 91-100, set./dez. 2000. Disponível em:

$<$ http://www.scielo.br/pdf/ci/v29n3/a09v29n3.pdf $>$. Acesso em: 20 mar. 2011.

WAL, T. V. Folksonomy definition and wikipedia. Disponível em:

<http://www.vanderwal.net/random/entrysel.php?blog=1750>. Acesso em: 04 jan. 2011.

ZENG, M. L. Knowledge organization systems (KOS). Knowledge Organization:

international journal devoted to concept theory, classification, indexing, and knowledge representation, Frankfurt, v. 35, n. 2-3, p. 160-182, 2008. 